\title{
Valorization of Dacryodes rostrata fruit through the characterization of its oil
}

\begin{abstract}
Dacryodes rostrata (kembayau) is an important food and oil resource for local communities in Borneo, but it is not commonly known to wider community. The objective of this work is to valorize kembayau fruit by evaluating the characteristics of the oil from the fruit. In this study, the physicochemical characteristics and the lipophilic essential nutrient; the fatty acid composition, vitamin $\mathrm{E}$ and beta-carotene content of oils obtained from the peel, pulp and seeds of kembayau fruits were studied. The pulp of the kembayau fruit contained highest proportion of oil, followed by peel and seed. Kembayau fruit contained vitamin E and had trace amount of beta-carotene. Besides, kembayau fruit oils were not toxic to BRL3A cells, provided hepatoprotection and reversed lipid peroxidation in paracetamol-induced toxicity. Our results suggest that kembayau can be a potential source for cooking oil as the physicochemical characteristics are comparable with commercial source such as oil palm.
\end{abstract}

Keyword: Beta-carotene; Dacryodes rostrate; Fatty acid profile; Kembayau fruits; Physicochemical characteristics; Vitamin E; Hepatoprotection 